\title{
Dynamic Stock Market Covariances in the Eurozone
}

\author{
Gregory Connor* and Anita Suurlaht \\ Department of Economics, Finance \& Accounting \\ National University of Ireland, Maynooth
}

May 30, 2012

\begin{abstract}
This paper examines the short-term dynamics, macroeconomic sensitivities, and longer-term trends in the variances and covariances of national equity market index daily returns for eleven countries in the Euro currency zone. We modify Colacito, Engle and Ghysel's Mixed Data Sampling Dynamic Conditional Correlation Garch model to include a new scalar measure for the degree of correlatedness in time-varying correlation matrices. We also explore the robustness of the findings with a less model-dependent realized covariance estimator. We find a secular trend toward higher correlation during our sample period, and significant linkages between macroeconomic and market-wide variables and dynamic correlation. One notable finding is that average correlation between these markets is lower when their average GDP growth rate is lower or when more of them have negative GDP growth.
\end{abstract}

JEL Classifications: C51, C58, G15.

Keywords: dynamic conditional correlation, multivariate GARCH, international stock market integration, European Monetary Union.

${ }^{*}$ Corresponding author. Tel: (353) 1 708-6662, Fax: (353) 1 708-3934, Email: Gregory.connor@nuim.ie. 


\section{Introduction}

This paper explores the changing magnitude of equity index return volatilities and correlations within the Eurozone, both in response to dynamic variation in the economic environment and in response to secular trends toward greater capital market integration. Although there are other regional economic cooperation agreements around the globe, the Eurozone is unique in the depth and breadth of its economic and financial integration, including the use of a common currency. This paper analyzes the equity market risk dynamics of this uniquely integrated regional capital market.

We use the Midas-Garch model of Engle et al. (2008) to model the dynamic volatilities of the daily returns of eleven Eurozone stock market indices. As in Colacito et al. (2011), we combine the Midas-Garch model with the Dynamic Conditional Correlation (DCC) model of Engle (2002) to model the dynamic correlation matrix of the returns. We modify the DCC model to include a new univariate measure of multivariate correlation magnitude. With this simplified DCC model, which is a special case of Engle's more general specification, we analyze the relationship between macroeconomic variables and the time-varying correlations between Eurozone markets.

As a robustness check, we also apply less model-dependent realized covariance estimators, together with the same univariate measure of correlation magnitude, and find reasonably consistent empirical results.

We find that covariance stationary, two-component Midas-Garch volatility models with Garch $(1,1)$ short-term components and mean-reverting, exponentiallyweighted medium-term components fit our daily equity index returns data sample reasonably well. There is an autoregressive pattern in our scalar measure of correlation magnitude. There is a strong positive trend toward higher correlation magnitudes across these Eurozone markets over our sample time period. We find some evidence for a "downside correlation" effect, so that, ceteris paribus, Eurozone markets seem to be more correlated when recent cumulative returns are on average lower within the region. We also find evidence for a positive dynamic link between cross-market average variance and correlation magnitude within the region. Interestingly, correlation magnitude varies positively with Eurozone GDP growth measures. In one specification of this effect, we find a negative link between Eurozone business downturns (the proportion of markets with negative quarterly GDP growth rates) and correlation magnitude. In an alternative, related, specification correlation magnitude is higher during quarters when the cross-country av- 
erage quarterly GDP growth rate is higher.

Our paper is related to several strands of the research literature. One topic of considerable interest concerns the level and secular trend in international capital market integration, e.g., Lessard (1974), Heston and Rouwenhorst (1994), Drummen and Zimmerman (1992), Beckers et al. (1996), Rouwenhorst (1999), Hopkins and Miller (2001) and Griffin and Karolyj (1998). Much of the work in this area has focussed upon European markets, reflecting the continent's six-decade experiment in politically-led regional economic integration.

Another relevant research strand examines international spillover effects in stock markets, e.g., King and Wadhwani (1990), Hamao et al. (1990), Baillie et al. (1993), Engle et al. (1994), Booth and Tse (1996), and Goetzmann et al. (2005). Related to this is the accumulated evidence that correlations between financial markets are significantly higher during periods of volatile markets, as in Ang and Bekaert (1999), Longin and Solnik (1995, 2001), and Capiello et al. (2006), and higher during "down" markets than during "up" markets, as found by Erb et al. (1994), Longin and Solnik (2001) and De Santis and Gerard (1997). Another related research area concerns empirical examination of the relationships between macroeconomic variables and stock market volatility, e.g., Officer (1973), Schwert (1989), Hamilton and Lin (1996) and Brandt and Kang (2004).

In terms of econometric technique, we utilize a covariance-stationary, twocomponent Garch-type model. The component specification distinguishes between short- and longer run sources of volatility. Engle and White (1999) proposed a Garch model with a short and long run component. Various two-component volatility models have been proposed by Ding and Granger (1996), Chernov et al. (2003), and Adrian and Rosenberg (2006). The MidasGarch component model was inspired by two earlier contributions, Ghysels et al. (2005) on Midas filter and Engle and Rangel (2008) on spline-Garch. Engle et al. (2008) formulate the Midas-Garch component specification that we employ.

For correlation modeling we use a variant of the Dynamic Conditional Correlation (DCC) model. Bollerslev (1990) develops a multivariate time series model with time varying conditional variances and covariances, but constant conditional correlations. Building upon this, Engle (2002) proposed the DCC model, in which conditional correlation is also time varying. Colacito et al. (2011) utilized these specifications and proposed a new class of component correlation models, the DCC-Midas correlation models. Our paper 
extends the DCC model by imposing a one-dimensional structure on the multivariate dynamic correlations. We find that our model is numerically easy to estimate by maximum likelihood, at least in the case of a modest number of asset returns (there are eleven assets in our application to Eurozone equity market indices). This may be due in part to the simplified one-dimensional dynamic correlation measure which we introduce in this paper.

Section two describes our main econometric model and estimation technique. Section three describes an alternative, realized-covariance-based estimator, also based on our one-dimensional dynamic correlation measure but employing a simpler estimation methodology. Section four describes our data and presents all our empirical findings. Section five summarizes the paper.

\section{A DCC-Midas-Garch Specification with Uni- variate Correlation Dynamics}

We adopt the Dynamic Conditional Correlation Midas-Garch model but add to it a univariate measure of dynamic correlatedness. We do this by imposing a particular functional form on the dynamics of the correlation matrix.

We observe an $n$-vector of returns $r_{t}$ on $n$ assets over the interval $t-1$ to $t$. We assume that the $n$-vector of returns $r_{t}$ has a time-constant vector of means $\mu$ and time-varying nonsingular covariance matrix $C_{t}$ :

$$
r_{t}=\mu+C_{t}^{1 / 2} \eta_{t}
$$

where $\eta_{t}$ is an i.i.d. mean-zero $n$-vector time series process with covariance matrix equal to the identity matrix. We denote the vector of demeaned returns by $\widetilde{r}_{t}$.

Let $s_{t}=\left(\sigma_{1 t}, \ldots, \sigma_{n t}\right)$ denote the $n$-vector of individual asset return volatilities for time $t$ returns based on time $t-1$ information, and let $\Omega_{t}=$

$\left\{\operatorname{Cov}_{t-1}\left(r_{i t} / \sigma_{i t}, r_{i t} / \sigma_{i t}\right), i, j=1, \ldots, n\right\}$ denote the conditional correlation matrix of returns, conditional on time $t-1$ information.

\subsection{A Review of Midas-Garch}

The starting point in Engle's DCC approach is to model the individual return volatilities separately. For the components of $s_{t}$ we use a model essentially identical to that in Colacito et al. (2011) and Engle et al. (2008): 
each individual return volatility follows a Midas-Garch model. Midas-Garch differs from standard Garch in allowing time $t$ "baseline" variance to vary slowly through time. This ameliorates a substantial flaw in standard Garch when applied to long time samples, in particular, the empirically untenable assumption in standard Garch that baseline variance is time-constant, see Taylor (1986).

Letting $h_{i t}$ denote baseline variance for asset $i$ at time $t-1$ for time $t$ returns; we assume that it is a weighted linear combination of unconditonal variance $h_{0 i}$ and lagged realized variances:

$$
h_{i t}=(1-\theta) h_{0 i}+\theta_{i} c\left(\omega_{i}\right) \sum_{k=1}^{K} \exp \left(-\omega_{i} k\right) R V_{i, t-n k}
$$

with estimable parameters $h_{0 i}, \theta_{i}$, and $\omega_{i}$, and where $R V_{i, t}$ denotes the $J$ period realized variance up to time $t$ :

$$
R V_{i t}=\frac{1}{J} \sum_{j=1}^{J} \widetilde{r}_{i, t-j}^{2}
$$

and $c\left(\omega_{i}\right)=\left(\sum_{k=1}^{K} \exp \left(-\omega_{i} k\right)\right)^{-1}$ ensures that the exponential weights sum to one. The model requires $h_{0 i}>0$ and $0 \leq \theta_{i}<1$ to guarantee a covariance stationary process.

The slowly-changing variate $h_{i t}$ captures the low-frequency component of volatility but misses short-term Garch effects. These are captured via a standard $\operatorname{Garch}(1,1)$ model with unit unconditional variance:

$$
g_{i t}=\left(1-\alpha_{i}-\beta_{i}\right)+\alpha_{i} g_{i t-1}+\beta_{i} \frac{\widetilde{r}_{i, t-1}^{2}}{h_{i t-1}},
$$

with $\alpha_{i}, \beta_{i} \geq 0$ and $\alpha_{i}+\beta_{i}<1$. The product of baseline variance and the short-term Garch effect gives time $t$ variance:

$$
\sigma_{i t}^{2}=h_{i t} g_{i t}
$$

\subsection{A Modified DCC Model with Univariate Dynamics}

We use $\operatorname{Diag}[x]$ to denote an $n x n$ diagonal matrix with the $n$-elements of the vector $x$ on the diagonal, and $\operatorname{diag}[X]$ to denote the diagonal matrix 
consisting of the diagonal elements of any square matrix $X$ with all nondiagonal elements set to zero. By definition the covariance matrix is the quadratic product of the volatilities and correlation matrix:

$$
C_{t}=\operatorname{Diag}\left[s_{t}\right] \Omega_{t} \operatorname{Diag}\left[s_{t}\right] .
$$

Building upon the constant conditional correlation model of Bollerslev (1990) (in which $\Omega_{t}=\Omega$, a time-constant matrix), Engle (2002) suggests modeling the correlation matrix separately from the volatilities and then combining them via (3) to produce a dynamic covariance matrix. Let $X_{1 t}, X_{2 t}$ denote two symmetric, positive semi-definite $n x n$ matrices at least one of which is strictly positive definite and let $m_{1 t}, m_{2 t}$ denote two strictly positive scalars. (We are using the case of two explanatory variables for notational convenience only; more or less are acceptable). Engle defines the quasi-correlation matrix $Q_{t}$ as the linear combination:

$$
Q_{t}=m_{1 t} X_{1 t}+m_{2 t} X_{2 t} .
$$

The matrix $Q_{t}$ is symmetric and positive definite but lacks one required property of a correlation matrix since the diagonal elements are not necessarily equal to one. Engle suggests a simple nonlinear transformation to impose this property while still maintaining symmetry and positive definiteness:

$$
\Omega_{t}=\operatorname{diag}\left[Q_{t}\right]^{-1 / 2} Q_{t} \operatorname{diag}\left[Q_{t}\right]^{-1 / 2}
$$

Equations (4) and (5) define Engle's dynamic conditional correlation (DCC) estimator. Together with models for the individual volatilies $s_{t}$, this gives a composite model of the dynamic covariance matrix.

Our model differs from standard DCC in the way we restrict the dynamics of the correlation matrix. Engle's DCC model is very clever, but is too highdimensional for our application. The major objective of our paper is to explore the changing magnitude of correlation within the Eurozone, both in response to the dynamically varying economic environment and in response to European capital market integration trends. In place of the $\frac{1}{2} n(n-1)$ dimensional correlation dynamics in (4) we want a univariate measure of time-varying correlation. This scalar measure of correlation magnitude should leave the pattern of correlation between individual markets essentially fixed. We now modify Engle's model to produce such a scalar measure.

We want to find a model for $\Omega_{t}$ with a simple one-dimensional state variable $m_{t}$ capturing the time variation in $\Omega_{t}$. When the univariate state 
variable $m_{t}$ is high, the correlations between markets are relatively strong, when $m_{t}$ is low, the correlations are relatively weak, and when $m_{t}$ equals zero the correlations are average. Except for this state variable the general "structure" of correlations is assumed invariant through time.

Let $\Omega_{0}$ denote the time-constant unconditional correlation matrix:

$$
\left(\Omega_{0}\right)_{i j}=\operatorname{cov}_{0}\left[\frac{\widetilde{r}_{i t}}{\sigma_{i t}}, \frac{\widetilde{r}_{j t}}{\sigma_{j t}}\right]_{i, j=1, ., n}=E_{0}\left[\widetilde{r}_{t}\left(\left(\operatorname{Diag}\left[s_{t}\right]\right)^{-2}\right) \widetilde{r}_{t}\right]
$$

where the 0 subscript denotes the unconditional information set. Let $U$ the $n x n$ matrix consisting entirely of ones. Our simple model for $\Omega_{t}$ is as follows:

$$
\Omega_{t}=\Omega_{0}+m_{t-1}\left(U-\Omega_{0}\right), \text { for }-1<m_{t-1}<1
$$

The variable $m_{t-1}$ is restricted to the interval $(-1,1)$. We must show that (7) meets Engle's condition (4) that $\Omega_{t}$ is a positive linear combination of positive-semidefinite matrices. Suppose that the following condition holds:

$$
2 \Omega_{0}-U \text { is strictly positive definite. }
$$

A necessary condition for this to hold is that all the off-diagonal elements of $\Omega_{0}$ are positive; in the case that they are all equal this is also a sufficient condition. Confirming that condition (8) holds is a straightforward empirical task, and is a condition easily met in our application to Eurozone equity markets. Note that (7) can be written as $\Omega_{t}=a_{t-1}\left(2 \Omega_{0}-U\right)+\left(1+a_{t-1}\right) U$ where $a_{t-1}=2\left(m_{t-1}-\frac{1}{2}\right)$. Since $U$ is positive semi-definite and $0<a_{t-1}<1$ the system (7) meets the positive definiteness criterion. Conveniently we do not need to use (5) since our construction always gives a matrix with units on the diagonal.

Figure 1 illustrates the model using the actual estimated unconditional correlation matrix described later. It shows all the pairwise correlations as $m_{t}$ varies between -1 and 1 ; with $m_{t}=0$ corresponding to the unconditional sample correlation. The model captures in a simple and intuitive way the notion that in some states of nature all correlations move higher, and in other states, lower. It provides a univariate measure of this dynamic correlation. It sacrifices the generality of Engle's original DCC (where all the correlations can move independently) in favour of greater simplicity and interpretability.

Our variant of the DCC model has some parallels to the Engle and Kelly (2011) Dynamic Equicorrelation (DECO) model. Our model, like the DECO 
model, is motivated by a desire for greater parsimony than the unrestricted DCC model. The DECO model does this by assuming that at each time point all correlations are equal; this produces a dynamic model of correlations which is truly univariate. In contrast, our model permits the unconditional correlation matrix to be unconstrained with full dimension, but imposes univariate dynamics on the movement of the conditional correlation matrix relative to its unconditional value. The difference in our approach relative to DECO reflects the difference in application: Engle and Kelly seek to model a very large cross-section of individual equities, whereas we want examine the dynamics in a moderate number (eleven) of national equity indices.

As in Engle et al. (2008), we impose a linear structure on $m_{t}$ based on a low-dimensional vector $x_{t}$ of explanatory variables (such as macroeconomic variates and financial market stress indicators):

$$
m_{t}=b^{\prime} x_{t}
$$

subject to $-1<m_{t}<1$. This mandates that the explanatory variables $x_{t}$ have bounded support and imposes implicit restrictions on the parameters $b$ (analogous to the positive-coefficient requirements of a GARCH model). It follows from (7) that the explanatory variables $x_{t}$ must have unconditional expectations of zero.

Our model for $\Omega_{t}$ consists of (6), (7), (8) and (9) with estimable parameters $a_{0}, b, \Omega_{0}$. In our application, the endogenous variable $m_{t}$ is daily but the explanatory variables are constant for all days within a quarterly frequency; this does not affect the econometric methodology.

Consider the average correlation at time $t$, found by averaging the offdiagonal elements of the time- $t$ correlation matrix:

$$
\text { avecorr }_{t}=\frac{1}{n(n-1)} \sum_{i \neq j}\left[\Omega_{t}\right]_{i j}
$$

As we show next, the linear dynamic equation for the correlation matrix

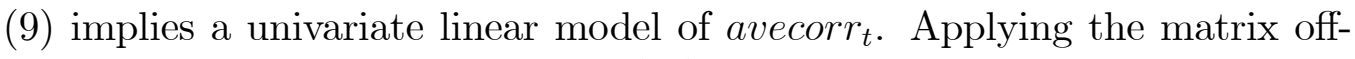
diagonal averaging transformation (10) to both sides of the dynamic correlation matrix equation (7) and rearranging, gives a variable we will call the correlation ratio; it is the deviation of time $t$ average correlation from its long-term average, divided by one minus the long-term average:

$$
\text { ratio }_{t}=\frac{\text { avecorr }_{t}-\text { avecorr }_{0}}{\left(1-\text { avecorr }_{0}\right)}=m_{t}
$$


Inserting ratio into (9) gives:

$$
\text { ratio }_{t}=b x_{t},
$$

so that equation (9) in the dynamic system implies this linear model of timevarying average correlation.

\subsection{A Maximum Likelihood Estimation Procedure}

We follow Engle (2002) and Colacito et al. (2011) in applying two-component maximum likelihood to estimate the DCC-Garch-Midas model. We begin by supposing that the innovation process $\eta_{t}$ is i.i.d. multivariate normal; it is unit variance and uncorrelated by definition; see (1). Weakening the assumption of normality gives rise to a quasi-maximum likelihood interpretation rather than true maximum likelihood. Recall that $C_{t}=\operatorname{Diag}\left[s_{t}\right] \Omega_{t} \operatorname{Diag}\left[s_{t}\right]$ where $C_{t}$ is the time- $t$ covariance matrix. Using a standard result, under i.i.d. multivariate normality of the innovations the data generating process for our sample return vector has log likelihood function:

$$
\begin{aligned}
L & =-\frac{1}{2}\left(\sum_{t=1}^{T}\left(n \log (2 \pi)+\log \left(\left|C_{t}\right|\right)+\widetilde{r}_{t}^{\prime} C_{t}^{-1} \widetilde{r}_{t}\right)\right) \\
& =-\frac{1}{2}\left(\sum _ { t = 1 } ^ { T } \left(n \log (2 \pi)+\log \left(\left|\operatorname{Diag}\left[s_{t}\right] \Omega_{t} \operatorname{Diag}\left[s_{t}\right]\right|\right)\right.\right. \\
& \left.\left.+\widetilde{r}_{t}\left(\operatorname{Diag}\left[s_{t}\right] \Omega_{t} \operatorname{Diag}\left[s_{t}\right]\right)^{-1} \widetilde{r}_{t}\right)\right)
\end{aligned}
$$

Let $\Theta_{1}=\left\{h_{0 i}, \theta_{i}, \omega_{i}, \alpha_{i}, \beta_{i}\right\}_{i=1, \ldots, n}$ denote the parameters of the Garch-Midas model, and $\Theta_{2}=\left(\Omega_{0}, a_{0}, b\right)$ the parameters of the dynamic correlation matrix model. Following Engle (2002) we use a two-component maximum likelihood approach. In the first step we use the individual time series of returns to estimate the Midas-Garch parameters $\Theta_{1}$ for each asset separately. Note that this is a collection of $n$ unrelated individual-asset Midas-Garch maximization likelihood estimation problems. Then in the second step we use these consistent, limited-information maximum likelihood values of $\Theta_{1}$ to substitute $\operatorname{Diag}\left[\widehat{s}_{t}\right]$ for $\operatorname{Diag}\left[s_{t}\right]$ in (13) to find the maximum likelihood estimate of $\Theta_{2}$.

The first-step estimation decomposes into a collection of individual Garchtype model estimation problems with additively separable log likelihood max- 
imization problems:

$$
\begin{aligned}
\widehat{\Theta}_{1 i} & =\underset{\widehat{\Theta}_{1 i}}{\arg \max } L_{1 i} \text { where } \\
L_{1 i} & =\left\{-\frac{1}{2}\left(\sum_{t=1}^{T}\left(\log (2 \pi)+\log \left(h_{i t}\right)+\frac{\widetilde{r}_{i t}^{2}}{h_{i t}}\right)\right\}\right.
\end{aligned}
$$

There are two commonly-used estimators for the covariance matrix of the parameters in (14). These are the inverse of the outer product of the score vector, and the inverse Hessian; under standard conditions either provides a consistent estimator:

$$
E\left[\left(\frac{\partial L_{1 i}}{\partial \widehat{\Theta}_{1 i}}\right)\left(\frac{\partial L_{1 i}}{\partial \widehat{\Theta}_{1 i}}\right)^{\prime}\right]^{-1}=E\left[\frac{\partial^{2} L_{1 i}}{\partial^{2} \widehat{\Theta}_{1 i}}\right]^{-1}=\operatorname{T} \bar{T} \operatorname{cov}\left[\widehat{\Theta}_{1 i}, \widehat{\Theta}_{1 i}^{\prime}\right]
$$

where $\bar{T}$ denotes approximately equal for large $T$ and relies on consistent estimates of $\widehat{\Theta}_{1 i}$ (see, e.g., Greene (2008)). As discussed next, we use the outer product of the score vector.

In the second step, we use the first-step estimates from (14) to compute $\widehat{s}_{t}$ and then substitute this for $s_{t}$ in (13) giving a maximum likelihood problem in the parameters $\Theta_{2}$ only. Engle (2002) notes that the standard errors of the coefficients in the second-step correlation matrix estimation are in general inconsistent due to the use of first-step estimated volatilities. Engle and Sheppard (2001) derive a consistent estimate of the covariance matrix of the estimated parameters in the second step by adjusting for the first-step estimation error:

$$
\begin{aligned}
& \operatorname{cov}\left[\widehat{\Theta}_{2}, \widehat{\Theta}_{2}^{\prime}\right]=E\left[\left(\frac{\partial L}{\partial \widehat{\Theta}_{2}}\right)\left(\frac{\partial L}{\partial \widehat{\Theta}_{2}}\right)^{\prime}\right]^{-1} E\left[y y^{\prime}\right] E\left[\left(\frac{\partial L}{\partial \widehat{\Theta}_{2}}\right)\left(\frac{\partial L}{\partial \widehat{\Theta}_{2}}\right)^{\prime}\right]^{-1} \\
& y=\frac{\partial L}{\partial \widehat{\Theta}_{2}}-E\left[\frac{\partial^{2} L}{\partial \Theta_{1} \partial \Theta_{2}}\right] E\left[\frac{\partial^{2} L_{1}}{\partial^{2} \Theta_{1}}\right]^{-1} \frac{\partial L_{1}}{\partial \widehat{\Theta}_{1}} .
\end{aligned}
$$

Note that this is the matrix product of the standard outer-product-based estimator (the first term in (16) as in (15)) times an adjustment matrix (the second and third terms).

Consider the special case in which expectations of all the cross-partial derivatives of the log likelihood function equal zero, $E\left[\frac{\partial^{2} L}{\partial \Theta_{1 j} \partial \Theta_{2 k}}\right]=0$ for all $j, k$ where $j, k$ run over all the elements of the parameter vectors $\Theta_{1}$ and $\Theta_{2}$, 
respectively. In this special case, the adjusted covariance matrix simplifies, and is equal to the unadjusted estimate using the outer product of the score vector:

$$
\operatorname{cov}\left[\widehat{\Theta}_{2}, \widehat{\Theta}_{2}^{\prime}\right]=E\left[\left(\frac{\partial L}{\partial \widehat{\Theta}_{2}}\right)\left(\frac{\partial L}{\partial \widehat{\Theta}_{2}}\right)^{\prime}\right]^{-1}
$$

which is easy to see since if $E\left[\frac{\partial^{2} L}{\partial \Theta_{1} \partial \Theta_{2}}\right]=0$ then $E\left[y y^{\prime}\right]=E\left[\left(\left(\frac{\partial L}{\partial \widehat{\Theta}_{2}}\right)\left(\frac{\partial L}{\partial \widehat{\Theta}_{2}}\right)^{\prime}\right]\right.$ and the adjustment matrix equals the identity matrix. This becomes relevant in our empirical application below.

\section{Model-Robust Alternative Estimators Us- ing Realized Covariances}

A drawback to the estimation approach of the last section is its reliance on numerical maximum likelihood and on the specific functional form of the DCC-Midas-Garch model. In this section we describe a stochastic-volatility variant of the model, treating the daily time interval as small and replacing the DCC-Midas-Garch specification with nonparametric, realized covariance estimators. This produces a model parallel to that of the previous sections, but which is easier to estimate, relying only on quarterly sample moments of daily returns and linear time series regression. It relies on the same onedimensional dynamic measure of average correlation, using the implication of this model for the dynamic correlation ratio (11). This model is parallel to, rather than identical to, the model of the last two sections, but the empirical findings provide a robustness check on the main results from the more complex estimation methodology.

Let $p_{t}$ denote a continuous-time $n$-vector stochastic process for the log prices of the stock indices, and suppose that this price vector follows Brownian motion with time-constant drift and time-varying covariance matrix $C_{t}$

$$
d p_{t}=\mu d t+C_{t} d z_{t}
$$

see Barndorff-Nielsen et al. (2011). Letting $\Delta$ denote a fixed-length, highfrequency return measurement interval define the return vector $r_{t, t+\Delta}=$ $p_{t+\Delta}-p_{t}$. Using a fixed finite window $Q$ define the integrated covariance 
matrix over the interval:

$$
C_{t-Q, t}=\frac{1}{Q} \int_{t-Q}^{t} C_{t} d t
$$

and the realized covariance estimator as the sample counterpart using highfrequency returns:

$$
\widehat{C}_{t-Q, t}=\frac{1}{(Q / \Delta)} \sum_{1 \leq j \leq \frac{Q}{\Delta}} r_{t-\Delta(j+1), t-\Delta j} r_{t-\Delta(j+1), t-\Delta j}^{\prime}
$$

From Barndorff-Nielsen et al. (2011), letting $\Delta \rightarrow 0$, with $Q$ fixed, and under appropriate regularity conditions, $\widehat{C}_{t-Q, t}$ is a consistent and asymptotically normal (CAN) estimate of $C_{t-Q, t}$. The dynamic correlation ratio (11) of the discrete daily model in the last section has an obvious realized-covariance analogue in this continuous-time model:

$$
\text { ratio }_{t-Q, t}=\frac{\text { avecorr }_{t-Q, t}-\text { avecorr }_{0}}{\left(1-\text { avecorr }_{0}\right)} .
$$

Note that the integrated correlation matrix, $\Omega_{t-Q, t}=\operatorname{Diag}\left[C_{t-Q, t}\right]^{-\frac{1}{2}}\left(C_{t-Q, t}\right) \operatorname{Diag}\left[C_{t-Q, t}\right]^{-\frac{1}{2}}$ and its average off-diagonal component are smooth transformations of $C_{t-Q, t}$. Hence, the preservation of CAN under smooth transformations guarantees that the same functions applied to $\widehat{C}_{t-Q, t}$ provide consistent asymptotically normal estimates of ratio $_{t-Q, t}$. We estimate the linear relation between ratio $_{t-Q, t}$ and and a set of zero-mean explanatory variables by time-series ordinary least squares regression at frequency $Q$. That is, we impose the data generating process:

$$
\text { ratio }_{t-Q, t}=b^{*} x_{t-Q, t}+\varepsilon_{t},
$$

where $x_{t-Q, t}$ is a set of explanatory variables measured over the same frequency $Q$, and $b^{*}$ is a vector of linear coefficents. These regression estimates provide alternative, less model dependent, parallels to the maximumlikelihood estimates of the dynamic model (9) described in the previous two subsections.

In our application, we use $\Delta$ equal to one day, and $Q$ (the window length) equal to the number of days in one quarter of the year (approximately 65 
trading days depending on the calendar). This matches the frequency of some of the independent variables in (12). There is not an exact match between the two models, but they capture related information over the same data history. We do not attempt to relate the simple regression specification (19) to the data generating process for individual returns (17). We view this regression model as a simpler alternative to the model described in the previous two sections, capturing some of the same empirical phenomena on the same data history.

\section{Data and Empirical Findings}

We use adjusted daily closing prices from December 31st 1991 to December 31st 2010 for eleven European equity indices, Austria, Belgium, Finland, France, Germany, Greece, Ireland, Italy, Netherlands, Portugal, and Spain, obtained from Datastream. (Although the Euro currency formally came into existence on January 1st 1999, the Maastricht Treaty committing signatory states to join the currency was drafted in December 1991, and signed by delegates of the member states in February 1992.) We compute daily log returns. The datastream database skips weekends and a few major holidays (Christmas and New Year's Day) but reproduces yesterday's closing price on other days on which a particular national exchange is closed. To partly correct for this, we ignore closing prices on days on which four or more of the eleven national exchanges are closed, and treat such a day the same as a weekend (the two-day return becomes a one-day return for the entire crosssection). This keeps the panel dataset balanced and seems to deal reasonably well with non-synchrony in the return computations (see below). There is a maximum two-hour time zone difference between the national markets in the sample; Ireland and Portugal are one hour behind the core European countries, and Greece is one hour ahead.

Table 1 shows the annualized means and standard deviations, skewness, excess kurtosis, and first four autocorrelations for each of the eleven returns series. Two markets (Greece and Portugal) have fairly high first-order autocorrelations, indicating illiquid pricing or stale pricing of the daily index. Table 2 shows the sample correlation matrix, above the diagonal, and the first-order autocovariance and crosscovariance adjusted correlation matrix below the diagonal. The diagonal elements are autocorrelation-consistent estimates of the annualized standard deviations. There is little difference 
between the adjusted and unadjusted correlations or standard deviations (compare to Table 1). This reflects the limited cross-correlation of returns, as shown in Table 3. By skipping days on which four or more markets are closed, and restricting our panel to European markets (with their similarity of trading hours), we avoid the large cross-correlations found in correlation analysis of global equity markets, see Martens and Poon (2001).

\subsection{The Midas-Garch Models of Individual Market In- dex Volatility}

Table 4 shows the estimates for the Midas-Garch model. For all countries the sum of the two Garch coefficient is well within the stationary boundary $\alpha_{i}+\beta_{i}<1$. The exponential weighting is close to 0 in most markets so that the optimal weighting is close to equal weighting of the four lagged fixedwindow realized variances. The estimated decay coefficient $\theta_{i}$ is close to $1 / 2$ in most markets. As a contrast, Table 4 shows standard Garch $(1,1)$ models. For all eleven markets, the estimated $\operatorname{Garch}(1,1)$ coefficients are closer to or (in one case) exceed the stationarity boundary $\alpha_{i}+\beta_{i}<1$. This shows one relative advantage of the Midas-Garch model.

Figure 2 illustrates the trends in Euro-area volatility using two proxies: the square root of the cross-sectional average of the predicted variances from the Midas-Garch models, and the square root of the cross-sectional average of the 65-day rolling window variances. Both proxies are annualized by multiplying by the square root of 261, the average number of trading days per year in our sample. The Midas-Garch volatilities are noticeably more variable through time, but the two proxies follow each other closely in terms of lower-frequency components.

\subsection{A Dynamic Model of Eurozone Equity Market Cor- relations}

Recall that the DCC-Midas-Garch maximum-likelihood estimation problem decomposes into Midas-Garch and the separate estimation of the correlation matrix dynamics. In this subsection we discuss the second-step estimation of the correlation matrix using the dynamic volatilities from the last subsection to standardize returns. For the dynamic correlation matrix model (9) we examine a variety of specifications. For explanatory variables we use a time 
trend, the average cumulative returns to the eleven indices using the previous 65 days of returns, the proportion of the eleven markets which had negative real GDP growth during the current quarter, the lagged correlation ratio (11) using the previous 65 days of daily returns, and the lagged average sample variance using the previous 65 daily returns. As an alternative specification, we also use the cross-sectional average of national GDP growth in the current quarter. This has a correlation of -.89 with the negative-growth-proportion variable, so we use one or the other of these two explanatory variables but not both simultaneously. All the explanatory variables are de-meaned.

With six potential explanatory variables, there is an unmanageable number of possible specifications by adding or dropping variables. We impose discipline on our specification search as follows. We include the lagged daily correlation ratio and time trend in all specifications. Both of these have a fairly strong empirical/theoretical foundation. For the other variables, the cumulative return measure, negative GDP growth proportion or average GDP growth, and lagged average variance, we try the combinations: none, each alone, and all three together. This gives seven specifications in total.

There are 55 estimable parameters in $\Omega_{0}$ since it is a symmetric $11 x 11$ matrix with unit diagonal. Additionally there are between two and five parameters in $b$ depending upon the specification. We use the sample correlation matrix $\widehat{\Omega}_{0}$ as an initial (and consistent) estimate. Next, we estimate $b$ consistently by limited information maximum likelihood applied to $L$ (see (13)) with the value of $\widehat{\Omega}_{0}$ held fixed at this initial estimate. Finally we use these initial estimates of $\widehat{b}$ and $\widehat{\Omega}_{0}$ and re-estimate all the parameters simultaneously by maximum likelihood. For all seven specifications, the maximum likelihood estimation problem converges quickly, and the $b$ estimates are relatively unaffected by the simultaneous estimation of $\widehat{\Omega}_{0}$, that is, the initial and final estimates of $b$ are quite similar. The initial estimates of $b$ and $\Omega_{0}$ are not shown but are available in Connor and Suurlaht (2012) along with other ancillary results and estimation code.

The results are presented in Table 6, using unadjusted one-step standard errors based on the outer product of the score vectors. (We will show in the next subsection that Engle's adjustment has negligible impact on the standard errors). Not surprisingly, there is an autocorrelation effect, captured in the positive coefficient on the lagged 65-day empirical correlation ratio. There is a strong positive trend in correlation magnitude over this time period within the Euro region. These are the two strongest findings. The "downside 
correlation" effect linking cumulative return negatively to correlation magnitude is only significant in the five-variable model including average GDP growth. When cumulative return is used without either of the GDP-based variables, the coefficient is significant with the "wrong" sign (this could be ascribed to a missing variable bias). There is a positive relationship between average variance and the dynamic correlation measure.

There is also a business-cycle-related effect: correlations are lower when the proportion of markets with negative GDP growth is higher. The same finding holds when average GDP growth is used as a replacement variable (with the opposite sign, obviously). This shows that, for some reason for which we do not have a ready theory, there seems to be greater diversity in the national index returns when several Eurozone economies are in a business cycle downturn or their average GDP growth is lower. This finding differentiates our results from those of Erb et al. (1994) on the dynamic correlations of G7 equity markets. Erb, Harvey and Viskanta use the Center for International Business Cycle Research national business cycle peak/trough indicator to divide monthly return data pairs (each G7 market matched with each of the other G7 markets in pairs) into three subsamples: both national markets in a macroeconomic expansion phase, both in a macroeconomic contraction phase, and mixed (one in each phase). They find that the return correlations are lowest in the expansion-expansion subsamples and highest in the contraction-contraction subsamples. Treating our proportion of markets with negative GDP growth as a contraction/expansion indicator, our results for the Eurozone find an opposite effect. We attribute this difference to the different nature of the capital market and macroeconomic links within the tightly-integrated Eurozone versus the G7. However, we do not claim to have a satisfactory macroeconomic-financial theory to explain the findings.

Suurlaht (2012) has applied exactly the same methodology as we use to G7 markets, and finds that a (somewhat weaker) positive integration trend is statistically significant for those markets, but the "downside correlation" effect and GDP-related effect are much weaker than for the Eurozone markets. Neither effect is statistically significant, or is only marginally significant, depending upon the specification.

\subsection{Adjusted Second-step Coefficient Standard Errors}

In this subsection we implement the adjustment to the second-step parameter standard errors proposed by Engle (2002). Note that there are 44 
parameters in the first-step parameter vector $\Theta_{1}$ (4 parameters per national market index and 11 national market indices). Consider either model 6 or 7 in Table 6, in which there are 60 parameters in the second-step parameter set $\Theta_{2}=\left(b, \Omega_{0}\right)$. In this case the matrix of expected cross-partial derivatives, $E\left[\frac{\partial^{2} L\left(\Theta_{1}, \Theta_{2}\right)}{\partial \Theta_{1 j} \partial \Theta_{2 h}}\right]$, has dimension $60 x 44$. This matrix is numerically somewhat cumbersome to compute since it links the two steps of the component maximum likelihood procedure. The other elements of (16) are straightforward to compute; the score vectors of the likelihood function are created naturally as part of numerical maximum likelihood. Let $d_{1 j}$ denote a 44 -vector with a one in element $j$ and zeros elsewhere, $d_{2 h}$ denote a $60-$ vector with a one in element $h$ and zeros elsewhere. For every combination $j, h$ of first and second stage parameters we perturb each individual parameter positively and negatively away from its pre-estimated value, and re-estimate the second-stage expected log likelihood $E\left[L\left(\Theta_{1}^{*}, \Theta_{2}^{*}\right)\right]$ using the time-series average as a consistent estimate of the expectation. A linear combination of perturbed values of the expected log likelihood gives an approximation to the cross-partial derivative matrix:

$$
\begin{aligned}
E\left[\frac{\partial^{2} L\left(\Theta_{1}, \Theta_{2}\right)}{\partial \Theta_{1 j} \partial \Theta_{2 h}}\right] & =\lim _{\epsilon_{j}, \epsilon_{h} \rightarrow 0} \frac{1}{4 \epsilon_{j} \epsilon_{h}}\left\{E\left[L\left(\Theta_{1}+d_{1 j} \epsilon_{1 j}, \Theta_{2}+d_{1 h} \epsilon_{2 h}\right)\right]\right. \\
& -E\left[L\left(\Theta_{1}+d_{1 j} \epsilon_{1 j}, \Theta_{2}-d_{2 h} \epsilon_{2 h}\right)\right] \\
& -E\left[L\left(\Theta_{1}-d_{1 j} \epsilon_{1 j}, \Theta_{2}+d_{2 h} \epsilon_{2 h}\right)\right] \\
+ & \left.E\left[L\left(\Theta_{1}-d_{1 j} \epsilon_{1 j}, \Theta_{2}-d_{2 h} \epsilon_{2 h}\right)\right]\right\}
\end{aligned}
$$

We use (20) to approximate the cross-partials numerically, using appropriately small values for $\epsilon_{j}, \epsilon_{h}$. We compute the second-step likelihood timeseries sample realizations for each of the $4 \cdot 60 \cdot 44=105600$ combinations of positive/negative parameter perturbations in (20) and take a time-series sample mean for each realized sample of log likelihood observations. The other terms of (16) are straightforward.

Table 7 compares the adjusted and unadjusted standard errors of the second-step coefficients for the two five-variable models (specifications 6 and 7) from Table 6 . The adjustment has a negligible impact, which is unsurprising when the nature of the adjustment is traced. The perturbation of a first-step parameter has only a very modest and indirect impact on the likelihood scores of second-step parameters. A perturbation to one of the first-step parameters modestly influences $\widehat{s}$ and this, in turn, very modestly influences 
correlations via (3), which can theoretically at least influence the regression coefficients in (9). To summarize our findings in this regard, Engle's adjustment is theoretically appealing, but it is time-consuming and cumbersome to implement and has negligible impact in this application.

\subsection{Alternative Estimates Using Realized Variances and Covariances}

Table 8 parallels Table 6 but using the fixed-window variances and covariances and quarterly linear regression (19) in place of the DCC-Midas-Garch model. The dependent variable is the correlation ratio for each calendar quarter, based on the sample correlation matrix of daily returns during the quarter. The lagged correlation ratio among the explanatory variables is lagged by one full calendar quarter. The other explanatory variables are contemporaneous with the dependent variable over the same quarter. Although the model and methodology are different, the findings mostly parallel those with the DCC-Midas-Garch model. The coefficients on the lagged correlation ratio and time trend are both positive and significant, as in the DCC-MidasGarch model. The coefficient on the proportion of markets with negative GDP growth is negative as in the DCC-Midas-Garch model. The alternative variable choice, average-GDP growth, has a positive and significant sign in the five-variable model but is not significant when used alone (in the DCC-Midas-Garch model it was positive and significant in both cases). The "downside correlation" effect is significant and negative (the expected sign) when used alone and in one of the two five-variable models.

\section{Summary}

This paper uses a new variant of the Dynamic Conditional Correlation Mixed Data Sampling Garch model (DCC-Midas-Garch) to examine the dynamic volatilities and correlations of daily equity index returns for eleven countries in the Eurozone over the sample period January 2nd 1992 to December 30th 2010.

We develop a new variant of Engle's DCC model which simplifies the structure of that model by imposing a univariate measure of the dynamic changes in the correlation matrix. We use this new univariate measure of 
dynamic correlation magnitude to relate the dynamic variation in average correlation of equity markets in Europe to relevant macroeconomic variables.

We find that European markets show a significant positive trend toward higher inter-market correlations over the 1991-2010 time period. There is time-series autocorrelation in the magnitude of cross-market return correlations. Correlations are higher when cross-country average variances are higher. A "downside correlation" effect, negatively linking cumulative returns to dynamic correlations, is significant in some but not all of our chosen specifications. Also, there is a significant business-cycle effect: cross-market correlations tend to be lower when a larger proportion of the economies are in a negative-growth quarter. Alternatively (using a slightly different specification) correlations are higher when cross-market average GDP growth is higher. It is interesting to theorize as to why lower GDP growth, captured either by average growth or the proportion of countries with negative growth, is dynamically related to greater diversity of returns across national stock markets within the tightly-integrated Eurozone.

\section{Acknowledgements}

We wish to acknowledge support from the Science Foundation of Ireland under grant 08/SRC/FM1389. We would like to thank Donal O'Neill and participants at the National University of Ireland Maynooth financial economics seminar series, the annual conference of the Irish Economic Association, and the Symposium on Time-varying Correlation and Volatility at the University of Wolverhampton for helpful comments. 


\section{References}

[1] Adrian, T., Rosenberg, J., 2006. Stock returns and volatility: Pricing the short-run and long-run components of market risk. Federal Reserve Bank of New York, New York.

[2] Ang, A., Bekaert, G., 1999. International asset allocation with timevarying correlations. In: NBER working paper series no w7056. National Bureau of Economic Research, Cambridge, Mass.

[3] Baillie, R.T., Bollerslev, T., Redfearn, M.R., 1993. Bear squeezes, volatility spillovers and speculative attacks in the hyperinflation $1920 \mathrm{~s}$ foreign exchange. Journal of International Money and Finance 12, 511521.

[4] Barndorff-Nielsen, O.E., Hansen, P.R., Lunde, A., Shephard, N., 2011. Multivariate realised kernels: Consistent positive semi-definite estimators of the covariation of equity prices with noise and non-synchronous trading. Journal of Econometrics 162, 149-169.

[5] Beckers, S., Connor, G., Curds, R., 1996. National versus global influences on equity returns. Financial Analysts Journal 52, 31-39.

[6] Bollerslev, T., 1990. Modelling the coherence in short-run nominal exchange rates: A multivariate generalized Arch model. Review of Economics and Statistics 72, 498-505.

[7] Booth, G.G., Tse, Y., 1996. Common volatility and volatility spillovers between U.S. and Eurodollar interest rates: Evidence from the futures market. Journal of Economics and Business 48, 299-312.

[8] Brandt, M.W., Kang, Q., 2004. On the relationship between the conditional mean and volatility of stock returns: A Latent VAR approach. Journal of Financial Economics 72, 217-257.

[9] Cappiello, L., Engle, R.F., Sheppard, K., 2006. Asymmetric dynamics in the correlations of global equity and bond returns. Journal of Financial Econometrics 4, 537-572.

[10] Chernov, M., Gallant, R.A., Ghysels, E., Tauchen, G., 2003. Alternative models for stock price dynamics. Journal of Econometrics 116, 225-257. 
[11] Colacito, R., Engle, R.F., Ghysels, E., 2011. A component model for dynamic correlations. Journal of Econometrics 164, 45-59.

[12] Connor, G. and A. Suurlaht, 2012. Ancillary results and estimation code for dynamic stock market covariances in the Eurozone, working paper, National University of Ireland, Maynooth.

[13] De Santis, G., Gerard, B., 1997. International asset pricing and portfolio diversification with time-varying risk. Journal of Finance 52, 1881-1912.

[14] Ding, Z., Granger, C.W.J., 1996. Modeling volatility persistence of speculative returns: A new approach. Journal of Econometrics 73, 185-215.

[15] Drummen, M., Zimmermann, H., 1992. The structure of European stock returns. Financial Analysts Journal 48, 15-26.

[16] Engle, R., 2002. Dynamic conditional correlation: A simple class of multivariate generalized autoregressive conditional heteroskedasticity models. Journal of Business \& Economic Statistics 20, 339-350.

[17] Engle, R.F., Ghysels, E., Sohn, B., 2008. On the economic sources of stock market volatility. In: American Finance Association 2008 New Orleans Meetings. American Finance Association, New Orleans.

[18] Engle, R.F., Ito, T., Lin, W.-L., 1994. Do bulls and bears move across borders? International transmission of stock returns and volatility. Review of Financial Studies 7, 507-538.

[19] Engle, R.F. and B. Kelly, 2010. Dynamic equicorrelation. Working paper No. 12-07, The University of Chicago Booth School of Business.

[20] Engle, R.F., Rangel, J.G., 2008. The Spline-GARCH model for lowfrequency volatility and its global macroeconomic causes. Review of Financial Studies 21, 1187-1222.

[21] Engle, R.F., Sheppard, K., 2001. Theoretical and empirical properties of dynamic conditional correlation multivariate GARCH. National Bureau of Economic Research Working Paper Series No. 8554.

[22] Engle, R.F., White, H., 1999. A Permanent and transitory component model of stock return volatility. In: Engle RF, Granger CWJ \& White H 
(eds.) Cointegration, causality, and forecasting: a festschrift in honour of Clive W.J. Granger. Oxford University Press, pp. 475-497.

[23] Erb, C.B., Harvey, C.R., Viskanta, T.E., 1994. Forecasting international equity correlations. Financial Analysts Journal 50, 32-45.

[24] Ghysels, E., Santa-Clara, P., Valkanov, R., 2005. There is a risk-return trade-off after all. Journal of Financial Economics 76, 509-548.

[25] Goetzmann, W. N., Li, L., Rouwenhorst, K.G., 2005. Long-term global market correlations. Journal of Business 78, 1-38.

[26] Greene, W.H., 2008. Econometric analysis. Pearson, Upper Saddle River, N.J.

[27] Griffin, J.M., Karolyi, A.G., 1998. Another look at the role of the industrial structure of markets for international diversification strategies. Journal of Financial Economics 50, 351-373.

[28] Hamao, Y., Masulis, R.W., Ng, V., 1990. Correlations in price changes and volatility across international stock markets. Review of Financial Studies 3, 281-307.

[29] Hamilton, J.D., Lin, G., 1996. Stock market volatility and the business cycle. Journal of Applied Econometrics 11, 573-93.

[30] Heston, S.L., Rouwenhorst, K.G., 1994. Does industrial structure explain the benefits of international diversification? Journal of Financial Economics 36, 3-27.

[31] Hopkins, P.J.B., Miller, C.H., 2001. Country, sector, and company factors in global equity portfolios. Research Foundation of AIMR.

[32] King, M.A., Wadhwani, S., 1990. Transmission of volatility between stock markets. Review of Financial Studies 3, 5-33.

[33] Lessard, D.R., 1974. World, national, and industry factors in equity returns. Journal of Finance 29, 379-91.

[34] Longin, F., Solnik, B., 1995. Is the correlation in international equity returns constant: 1960-1990? Journal of International Money and Finance 14, 3-26. 
[35] Longin, F., Solnik, B., 2001. Extreme correlation of international equity markets. Journal of Finance 56, 649-676.

[36] Martens, M., Poon, S.-H., 2001. Returns synchronization and daily correlation dynamics between international stock markets. Journal of Banking and Finance 25, 1805-1827.

[37] Officer, R.R., 1973. The variability of the market factor of the New York Stock Exchange. Journal of Business 46, 434-453.

[38] Rouwenhorst, K.G., 1999. European equity markets and the EMU. Financial Analysts Journal 55, 57-64.

[39] Schwert, G.W., 1989. Why does stock market volatility change over time? Journal of Finance 44, 1115-53.

[40] Suurlaht, A. 2012. Dynamic stock market covariances in the G7, working paper, National University of Ireland Maynooth.

[41] Taylor, S., 1986. Modelling financial time series. John Wiley \& Sons, New York. 
Table 1: Summary Statistics

\begin{tabular}{|c|c|c|c|c|c|c|c|c|}
\hline Series & $\begin{array}{l}\text { Annualized } \\
\text { Mean Return }\end{array}$ & $\begin{array}{c}\text { Annualized } \\
\text { Std Deviation }\end{array}$ & Skewness & $\begin{array}{l}\text { Excess } \\
\text { Kurtosis }\end{array}$ & $\rho_{1}$ & $\rho_{2}$ & $\rho_{3}$ & $\rho_{4}$ \\
\hline Austria & 6.71 & 21.80 & -0.37 & 8.71 & 0.0745 & -0.0354 & -0.0064 & 0.0162 \\
\hline Belgium & 4.81 & 19.08 & 0.04 & 7.20 & 0.0886 & -0.0097 & -0.0447 & 0.0230 \\
\hline Finland & 13.25 & 30.08 & -0.36 & 6.76 & 0.0286 & -0.0209 & -0.0161 & 0.0335 \\
\hline France & 4.35 & 23.16 & 0.01 & 4.78 & -0.0119 & -0.0414 & -0.0541 & 0.0373 \\
\hline Germany & 8.40 & 23.86 & -0.11 & 4.83 & -0.0164 & -0.0329 & -0.0180 & 0.0418 \\
\hline Greece & 2.91 & 27.15 & -0.12 & 3.89 & 0.1305 & -0.0159 & -0.0129 & 0.0278 \\
\hline Ireland & 4.07 & 21.03 & -0.62 & 9.53 & 0.0665 & 0.0007 & 0.0018 & 0.0124 \\
\hline Italy & 3.91 & 23.76 & -0.02 & 4.10 & 0.0270 & -0.0029 & -0.0233 & 0.0697 \\
\hline Netherlands & 5.85 & 23.08 & -0.13 & 6.54 & -0.0036 & -0.0227 & -0.0570 & 0.0479 \\
\hline Portugal & 8.40 & 16.30 & -0.33 & 12.86 & 0.1053 & 0.0184 & 0.0248 & 0.0438 \\
\hline Spain & 7.52 & 22.98 & -0.02 & 5.75 & 0.0191 & -0.0394 & -0.0323 & 0.0202 \\
\hline
\end{tabular}

Notes: Summary statistics including the first four autocorrelations for the eleven Eurozone stock market index daily $\log$ return series over the sample period from January 2, 1992 to December 30, 2010 (4788 observations).

\section{Table 2: The Sample Correlation Matrix and Annualized Standard Deviations}

$$
\begin{aligned}
& \begin{array}{lllllllllll}
R_{1 t} & R_{2 t} & R_{3 t} & R_{4 t} & R_{5 t} & R_{6 t} & R_{7 t} & R_{8 t} & R_{9 t} & R_{10 t} & R_{11 t}
\end{array}
\end{aligned}
$$

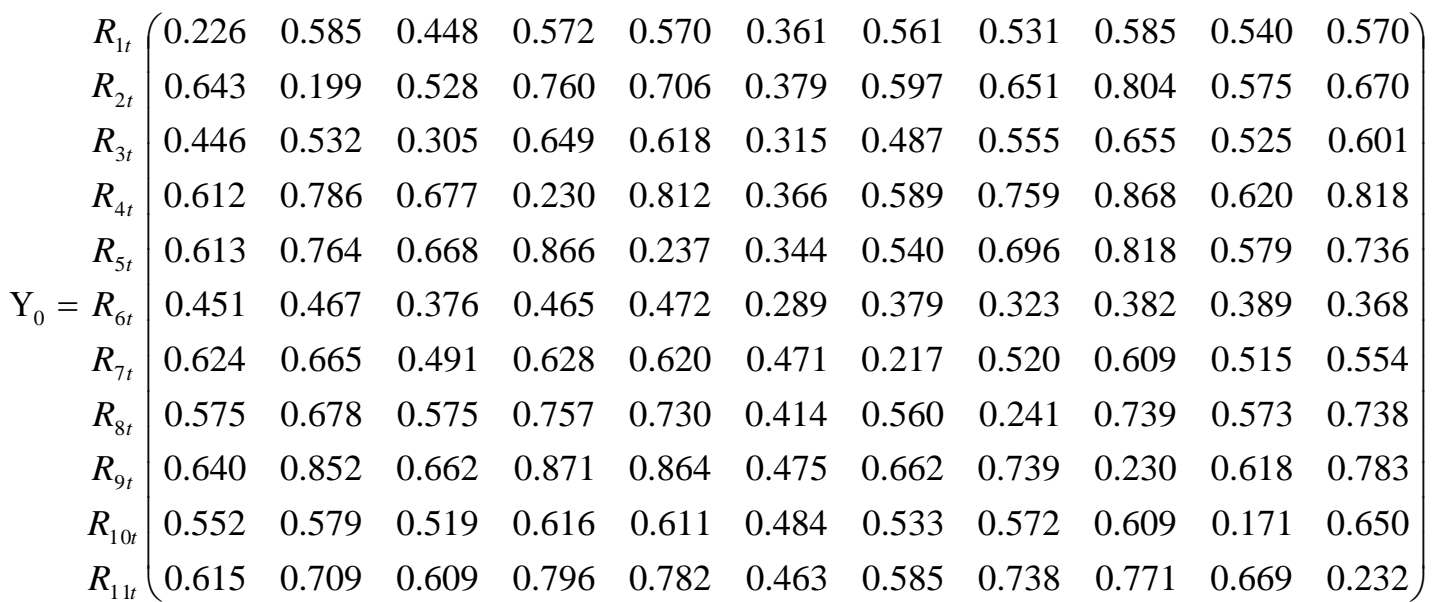

Notes: Sample correlation matrix for the eleven Eurozone stock market index return series (1. Austria 2.Belgium 3.Finland 4.France 5.Germany 6.Greece 7.Ireland 8.Italy 9.Netherlands 10.Portugal 11.Spain) over the sample period from January 2, 1992 to December 30, 2010. Sample correlations of national stock index returns are above the diagonal, and first-order autocovariance and cross-covariance adjusted correlations below the diagonal. The diagonal elements are first-order autocovariance-consistent estimates of the annualized standard deviations. 
Table 3: Cross-Correlation Matrix

\begin{tabular}{|c|c|c|c|c|c|c|c|c|c|c|c|}
\hline & $R_{l t-1}$ & $R_{2 t-1}$ & $R_{3 t-1}$ & $R_{4 t-1}$ & $R_{5 t-1}$ & $R_{6 t-1}$ & $R_{7 t-1}$ & $R_{8 t-1}$ & $R_{9 t-1}$ & $R_{10 t-1}$ & $R_{l l t-1}$ \\
\hline$R_{1 t-1}$ & $(0.075$ & -0.004 & -0.020 & -0.050 & -0.040 & 0.709 & 0.043 & -0.020 & -0.022 & 0.007 & -0.034 \\
\hline$R_{2 t-1}$ & 0.115 & 0.089 & 0.045 & 0.011 & 0.018 & 0.121 & 0.114 & 0.032 & 0.039 & 0.065 & 0.009 \\
\hline$R_{3 t-1}$ & 0.040 & -0.011 & 0.029 & -0.015 & -0.017 & 0.079 & 0.052 & -0.001 & -0.016 & 0.023 & -0.019 \\
\hline$R_{4 t-1}$ & 0.108 & 0.044 & 0.049 & -0.012 & 0.017 & 0.114 & 0.104 & 0.016 & 0.009 & 0.055 & -.008 \\
\hline$R_{5 t-1}$ & 0.099 & 0.066 & 0.071 & 0.025 & -0.016 & 0.138 & 0.126 & 0.031 & 0.043 & 0.079 & 0.023 \\
\hline$=R_{6 t-1}$ & 0.065 & 0.018 & 0.011 & 0.012 & 0.016 & 0.131 & 0.055 & 0.025 & 0.009 & 0.052 & 0.010 \\
\hline$R_{7 t-1}$ & 0.063 & 0.004 & -0.024 & -0.048 & -0.032 & 0.083 & 0.067 & -0.017 & -0.023 & 0.001 & -0.034 \\
\hline$R_{8 t-1}$ & 0.093 & 0.034 & 0.037 & -0.012 & 0.007 & 0.099 & 0.083 & 0.027 & 0.009 & 0.055 & -0.003 \\
\hline$R_{9 t-1}$ & 0.099 & 0.045 & 0.031 & -0.014 & -0.005 & 0.113 & 0.097 & 0.000 & -0.004 & 0.043 & -0.015 \\
\hline$R_{10 t-1}$ & 0.055 & -0.005 & 0.005 & -0.032 & -0.021 & 0.101 & 0.063 & -0.019 & -0.021 & 0.105 & -0.027 \\
\hline$R_{11 t-1}$ & 0.107 & 0.042 & 0.041 & -0.011 & 0.023 & 0.119 & 0.091 & 0.020 & 0.009 & 0.087 & 0.191 \\
\hline
\end{tabular}

Notes: Cross-correlations for the eleven Eurozone stock market index return series (1. Austria 2.Belgium 3.Finland 4.France 5.Germany 6.Greece 7.Ireland 8.Italy 9.Netherlands 10. Portugal 11 .Spain) over the sample period from January 2, 1992 to December 30, 2010. The diagonal elements are sample estimates of the firstorder autocorrelations. 


\section{Table 4: Midas-Garch Coefficient Estimates}

\begin{tabular}{|ccccc|}
\hline & $\boldsymbol{A}$ & $\boldsymbol{\beta}$ & $\boldsymbol{\theta}_{\boldsymbol{I}}$ & $\boldsymbol{\Omega}$ \\
\hline Austria & 0.11127 & 0.86022 & 0.54449 & -0.00355 \\
& $(13.17094)$ & $(75.03387)$ & $(6.73553)$ & $(-0.01041)$ \\
Belgium & 0.13268 & 0.84256 & 0.46776 & 0.89665 \\
& $(16.92474)$ & $(82.07313)$ & $(6.1407)$ & $(1.84557)$ \\
Finland & 0.07518 & 0.90306 & 0.81930 & 0.42064 \\
& $(20.64728)$ & $(145.8165)$ & $(14.80239)$ & $(1.57613)$ \\
France & 0.07758 & 0.90912 & 0.35795 & 0.31148 \\
& $(11.6316)$ & $(102.45957)$ & $(2.58299)$ & $(0.55674)$ \\
Germany & 0.09387 & 0.88731 & 0.47957 & 0.41147 \\
& $(13.87461)$ & $(98.61603)$ & $(4.46619)$ & $(0.87202)$ \\
Greece & 0.14410 & 0.79593 & 0.79747 & 0.32651 \\
& $(14.23207)$ & $(55.93516)$ & $(19.42899)$ & $(1.49283)$ \\
Ireland & 0.08239 & 0.89804 & 0.55263 & -0.04928 \\
& $(16.03312)$ & $(127.34827)$ & $(8.20791)$ & $(-0.15872)$ \\
Italy & 0.11068 & 0.86887 & 0.59665 & 0.58016 \\
& $(12.44145)$ & $(73.56442)$ & $(6.98272)$ & $(1.44295)$ \\
Netherlands & 0.10720 & 0.87572 & 0.57756 & 0.63954 \\
& $(14.18318)$ & $(92.62391)$ & $(6.6847)$ & $(1.48048)$ \\
Portugal & 0.16607 & 0.80362 & 0.58411 & 0.68731 \\
& $(25.59861)$ & $(96.88936)$ & $(10.08113)$ & $(2.13498)$ \\
Spain & 0.10353 & 0.87091 & 0.51957 & 0.96486 \\
& $(13.2313)$ & $(79.51477)$ & $(6.85726)$ & $(1.45853)$ \\
\hline
\end{tabular}

Notes: Individual Midas-Garch models are fitted to eleven Eurozone stock market indices using quasi-maximum likelihood estimation. Each Midas-Garch model is composed of several equations with a parameter space $\Theta=$ $\{\alpha, \beta, \theta, \omega\} . \mathrm{h}_{\mathrm{it}}$ denotes the baseline variance for asset $\mathrm{i}$ at time $\mathrm{t}-1$ for time $\mathrm{t}$ returns capturing the low-frequency component of volatility: $\mathbf{h}_{\mathrm{it}}=\left(\mathbf{1}-\boldsymbol{\theta}_{\boldsymbol{i}}\right) \boldsymbol{h}_{\boldsymbol{o i}}+\boldsymbol{\theta}_{\boldsymbol{i}} \boldsymbol{c}\left(\boldsymbol{\omega}_{\boldsymbol{i}}\right) \sum_{\boldsymbol{k}=\mathbf{1}}^{\mathbf{4}} \exp \left(-\boldsymbol{\omega}_{\mathrm{i}} \mathbf{k}\right) \mathbf{R} \mathbf{V}_{\mathrm{i}, \mathrm{t}-\mathrm{nk}}$, where $\mathrm{RV}_{\mathrm{it}}$ denotes the 65day realized variance up to day $\mathrm{t}: \mathbf{R} \mathbf{V}_{\mathbf{i t}}=\sum_{j=0}^{\mathbf{6 5}} \tilde{\mathbf{r}}_{\mathbf{i}, \mathbf{t}-\mathbf{j}}^{\mathbf{2}}$. Short-term Garch effects are captured via a standard $\operatorname{Garch}(1,1)$ model: $\boldsymbol{g}_{i t}=(\mathbf{1}-\boldsymbol{\alpha}-\boldsymbol{\beta})+\boldsymbol{\alpha}_{\boldsymbol{i}} \boldsymbol{g}_{\boldsymbol{i}, \boldsymbol{t}-\mathbf{1}}+\boldsymbol{\beta}_{\boldsymbol{i}} \frac{\tilde{r}_{\boldsymbol{i}, \boldsymbol{t}-\mathbf{1}}^{2}}{\boldsymbol{h}_{\boldsymbol{i}, \boldsymbol{t}-\mathbf{1}}}$. The t-statistics are reported in parentheses below the coefficient estimates. 
Table 5: Garch(1,1) Coefficient Estimates

\begin{tabular}{|lccc|}
\hline & $\mathbf{c}$ & $\boldsymbol{\alpha}$ & $\boldsymbol{\beta}$ \\
\hline Austria & 0.00000 & 0.10694 & 0.87563 \\
& $(5.57982)$ & $(10.61244)$ & $(77.05259)$ \\
Belgium & 0.00000 & 0.11428 & 0.87307 \\
& $(5.63099)$ & $(11.65358)$ & $(83.80542)$ \\
Finland & 0.00000 & 0.06279 & 0.93507 \\
& $(3.59846)$ & $(9.00308)$ & $(134.70374)$ \\
France & 0.00000 & 0.07270 & 0.91880 \\
& $(4.21632)$ & $(10.19124)$ & $(117.51801)$ \\
Germany & 0.00000 & 0.09300 & 0.89690 \\
& $(5.53149)$ & $(10.90098)$ & $(102.59965)$ \\
Ireland & 0.00001 & 0.14006 & 0.84882 \\
& $(5.6409)$ & $(10.15294)$ & $(61.27865)$ \\
Italy & 0.00000 & 0.08243 & 0.90878 \\
& $(5.09238)$ & $(10.21416)$ & $(101.83785)$ \\
Netherlands & 0.00000 & 0.10821 & 0.88742 \\
& $(4.47576)$ & $(10.84912)$ & $(90.02237)$ \\
Portugal & 0.00000 & 0.09863 & 0.89497 \\
& $(4.9819)$ & $(12.14323)$ & $(109.75847)$ \\
Spain & 0.00000 & 0.17532 & 0.83143 \\
& $(5.81078)$ & $(12.18645)$ & $(67.68329)$ \\
& 0.00000 & 0.10263 & 0.88493 \\
& $(5.41381)$ & $(10.34265)$ & $(81.99908)$ \\
\hline
\end{tabular}

Notes: Individual Garch $(1,1)$ models are fitted to eleven Eurozone stock market indices using quasi-maximum likelihood estimation. The parameter space for each $\operatorname{Garch}(1,1)$ model is $\Phi=\{\mathrm{c}, \alpha, \beta\}$. The standard $\operatorname{Garch}(1,1)$ model is defined as: $\boldsymbol{h}_{\boldsymbol{i t}}=\boldsymbol{C}+\boldsymbol{\alpha}_{\boldsymbol{i}} \boldsymbol{h}_{\boldsymbol{i}, \boldsymbol{t}-\mathbf{1}}+\boldsymbol{\beta}_{\boldsymbol{i}} \frac{\tilde{r}_{i, t-\mathbf{1}}^{2}}{\boldsymbol{h}_{i, t-1}}$ where $h_{i t}$ is the conditional variance. The t-statistics are reported in parentheses below the coefficient estimates. 
Table 6: Daily Models of Dynamic Correlation Magnitude

\begin{tabular}{|c|c|c|c|c|c|c|c|}
\hline & 1 & 2 & 3 & 4 & 5 & 6 & 7 \\
\hline \multirow[t]{2}{*}{ ratio $_{t-1}$} & 0.5181 & 0.5330 & 0.5086 & 0.5070 & 0.5750 & 0.4958 & 0.5482 \\
\hline & (20.8918) & $(20.5290)$ & (19.6310) & (19.6679) & (22.4218) & $(18.7651)$ & (20.4794) \\
\hline \multirow[t]{2}{*}{ trend $_{t}$} & 0.0320 & 0.0316 & 0.0323 & 0.0362 & 0.0310 & 0.0364 & 0.0323 \\
\hline & (18.4682) & (18.1130) & $(18.3673)$ & (19.0318) & (17.7246) & (19.2757) & (17.8254) \\
\hline cumret $_{t-1}$ & & $\begin{array}{c}0.0024 \\
(2.2649)\end{array}$ & & & & $\begin{array}{c}0.0005 \\
(0.2533)\end{array}$ & $\begin{array}{c}-0.0045 \\
(-2.5038)\end{array}$ \\
\hline $\operatorname{negGDP}_{t}$ & & & & $\begin{array}{c}-0.0624 \\
(-4.9480)\end{array}$ & & $\begin{array}{l}-0.0744 \\
(-3.8709)\end{array}$ & \\
\hline avegrowth $_{t}$ & & & & & $\begin{array}{c}0.0027 \\
(5.8862)\end{array}$ & & $\begin{array}{c}0.0047 \\
(7.1487)\end{array}$ \\
\hline $\operatorname{avevar}_{t-1}$ & & & $\begin{array}{c}0.1077 \\
(1.4118)\end{array}$ & & & $\begin{array}{c}0.2419 \\
(2.5504)\end{array}$ & $\begin{array}{c}0.2454 \\
(2.6086)\end{array}$ \\
\hline
\end{tabular}

Notes: The table reports estimated coefficients for the dynamic model of the correlation magnitudes using maximum likelihood. The sample period is January 2, 1992 to December 30, 2010. The seven columns correspond to seven different specifications and differ only in the choice of the explanatory variables. Dependent variable is the dynamic correlation magnitude for all seven regressions. The six macroeconomic variables are a lagged correlation ratio (using the previous 65 daily returns), a time trend, the average of the cumulative returns to the eleven indices over the previous 65 days, the contemporaneous proportion of the eleven markets which had negative real GDP growth during the quarter, the crosssectional average of national GDP growth in the current quarter, and the lagged average sample variance (using the previous 65 daily returns) between the eleven markets. The t-statistics are reported in parentheses below the coefficient estimates.

Table 7: Effect of Adjusting for the First-Step Estimation Error

\begin{tabular}{|c|c|c|c|}
\hline \multicolumn{4}{|c|}{ Specification 6} \\
\hline & Unadjusted St Deviations & Adjusted St Deviations & \% Difference \\
\hline ratiot $_{\mathrm{t}-1}$ & 0.02642365 & 0.02642774 & $0.0155 \%$ \\
\hline trend $_{\mathrm{t}}$ & 0.00188942 & 0.00188939 & $-0.0016 \%$ \\
\hline cumret $_{\mathrm{t}-1}$ & 0.00193435 & 0.00193489 & $0.0281 \%$ \\
\hline avevar $_{\mathrm{t}-1}$ & 0.09485253 & 0.09487655 & $0.0253 \%$ \\
\hline NegGDP $_{t}$ & 0.01922016 & 0.01922470 & $0.0236 \%$ \\
\hline \multicolumn{4}{|c|}{ Specification 7} \\
\hline & Unadjusted St Deviations & Adjusted St Deviations & \% Difference \\
\hline ratio $_{\mathrm{t}-1}$ & 0.02676794 & 0.02677458 & $0.0248 \%$ \\
\hline trend $_{\mathrm{t}}$ & 0.00180933 & 0.00180947 & $0.0077 \%$ \\
\hline cumret $_{\mathrm{t}}$ & 0.00181604 & 0.00181634 & $0.0166 \%$ \\
\hline avevar $_{\mathrm{t}-1}$ & 0.09407798 & 0.09412734 & $0.0525 \%$ \\
\hline avegrowth $_{\mathrm{t}}$ & 0.00066152 & 0.00066161 & $0.0133 \%$ \\
\hline
\end{tabular}

Table 7 compares the adjusted and unadjusted standard errors of the second-step coefficients for the dynamic correlation magnitude models 6 and 7 from Table 6 . The standard errors of the coefficients in the second-step correlation matrix estimation are in general inconsistent due to the use of first-step estimated volatilities (Engle(2002)). To adjust for the firststep estimation error the standard outer product of the score vector (the chosen estimator for the covariance matrix of coefficients from the Midas-Garch model) is multiplied by an adjustment matrix (see equation (19)). The variables are the same as in Table 6. 
Table 8: Quarterly Models of the Dynamic Correlation Ratio

\begin{tabular}{|c|c|c|c|c|c|c|c|}
\hline & 1 & 2 & 3 & 4 & 5 & 6 & 7 \\
\hline \multirow[t]{2}{*}{ qratio $_{t-1}$} & 0.3085 & 0.3382 & 0.2146 & 0.3320 & 0.3058 & 0.2761 & 0.3063 \\
\hline & $(2.7501)$ & $(3.2657)$ & (1.9943) & (2.8824) & (2.3809) & $(2.6351)$ & $(2.5949)$ \\
\hline \multirow[t]{2}{*}{$\operatorname{trend}_{t}$} & 0.0424 & 0.0384 & 0.0447 & 0.0418 & 0.0412 & 0.0415 & 0.0400 \\
\hline & $(5.2411)$ & $(5.1071)$ & (5.9187) & $(4.9754)$ & $(4.5892)$ & $(5.7010)$ & $(4.8686)$ \\
\hline \multirow[t]{2}{*}{ qcumret $_{t}$} & & -0.0619 & & & & -0.0404 & -0.0395 \\
\hline & & $(-3.7631)$ & & & & $(-2.0710)$ & $(-1.7768)$ \\
\hline \multirow[t]{2}{*}{$\operatorname{NegGDP}_{t}$} & & & & -0.0495 & & -0.2351 & \\
\hline & & & & $(-0.5582)$ & & $(-2.6943)$ & \\
\hline \multirow[t]{2}{*}{ avegrowth $_{t}$} & & & & & 0.0012 & & 0.0110 \\
\hline & & & & & $(0.3068)$ & & (2.6309) \\
\hline \multirow[t]{2}{*}{ qavevar $_{t}$} & & & 6.0117 & & & 5.8118 & 6.3577 \\
\hline & & & $(3.5379)$ & & & $(2.6643)$ & $(2.7210)$ \\
\hline Adj. R2 & 0.774 & 0.809 & 0.805 & 0.762 & 0.662 & 0.828 & 0.753 \\
\hline SSR & 2.484 & 2.076 & 2.116 & 2.372 & 2.219 & 1.811 & 1.567 \\
\hline
\end{tabular}

Notes: Table 8 reports estimated coefficients for the time series quarterly regressions to explain the movement in crosssectional average correlation, where the correlations are estimated using one quarter of daily returns. Each quarter consists of the trading days in a nonoverlapping three-month period, starting with January -March. The sample period is January 2 , 1992 to December 30, 2010. The seven columns correspond to seven different specifications and differ only in the choice of

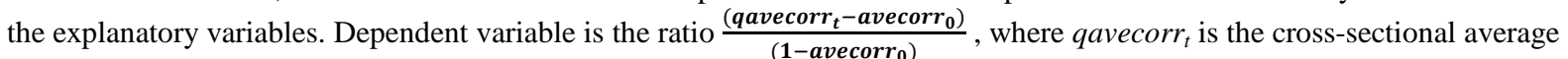
correlation for all six regressions and avecorr $_{0}$ is the average cross-sample correlation. The six independent variables are the lagged correlation ratio for each calendar quarter, a time trend, the average of the contemporaneous quarterly returns to the eleven indices, the contemporaneous proportion of the eleven markets which had negative real GDP growth during the quarter, the cross-sectional average of national GDP growth in the current quarter, and the contemporaneous average sample variance (also using one quarter of daily returns) between the eleven markets. The t-statistics are reported in parentheses below the coefficient estimates. The last two rows report the adjusted $\mathrm{R}^{2}$ and the sum of squared residuals. 
Figure 1: Depiction of the Correlations of Returns as a Function of $\mathbf{m}_{\mathbf{t}}$

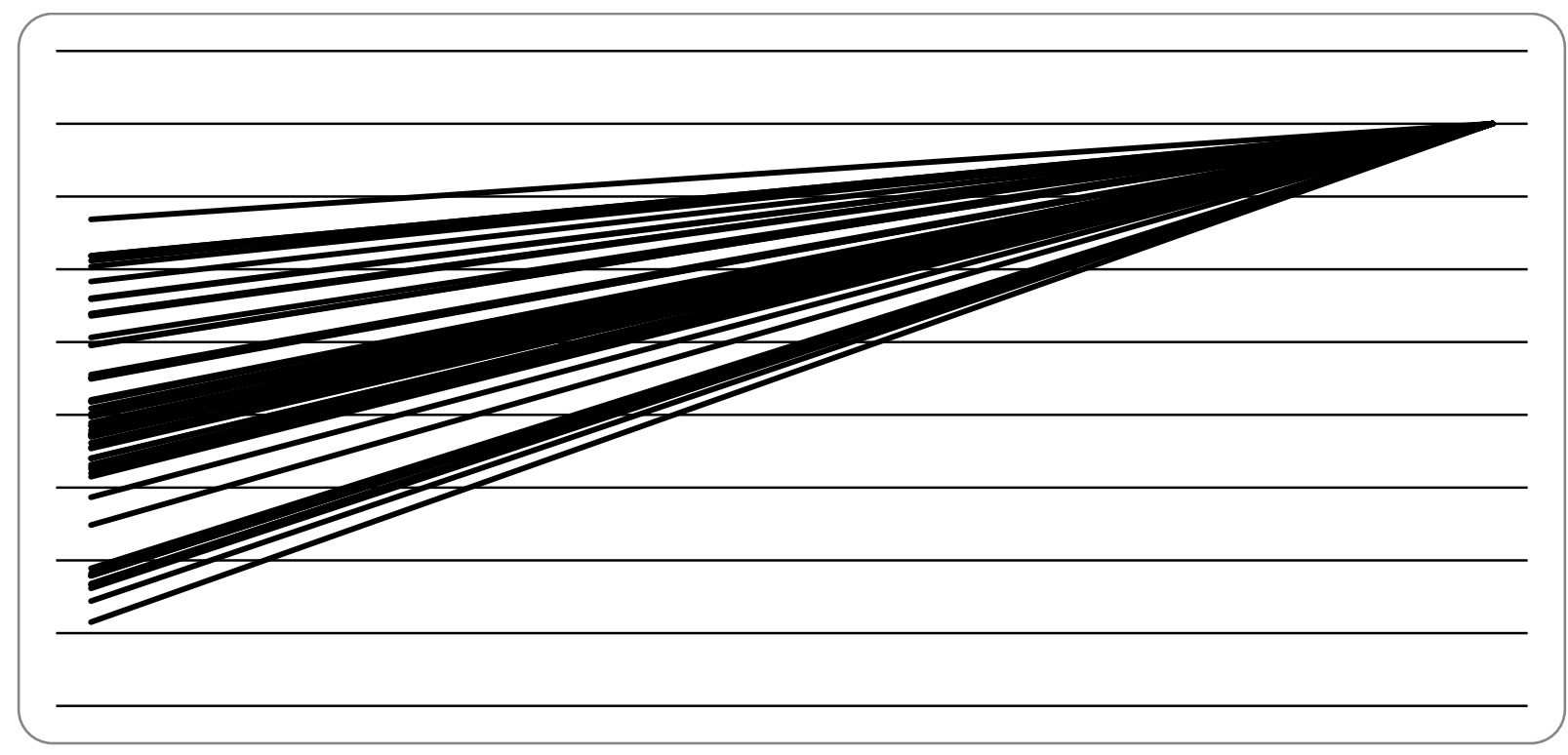

Notes: The graph illustrates the correlation within all country pairs in our sample as a function of the correlation magnitude variable, $\mathrm{m}_{\mathrm{t}}$. The correlations follow the simple model for $\Omega_{\mathrm{t}}: \Omega_{\mathrm{t}}=\Omega_{0+} \mathrm{m}_{\mathrm{t}-1}\left(\mathrm{U}-\Omega_{0}\right)$, for $-1<\mathrm{m}_{\mathrm{t}-1}<1$. See Table 2 for individual correlation coefficients between countries.

Figure 2: Midas-Garch and Rolling Window Annualized Return Standard Deviations

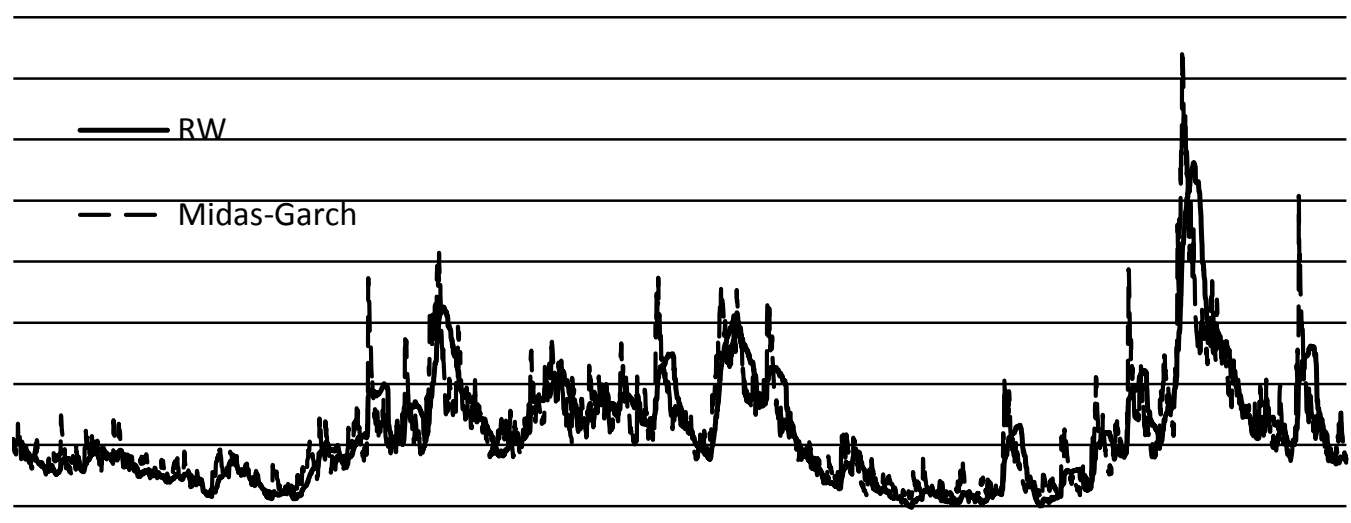

Notes: The figure shows the cross-sectional average of the annualized predicted return standard deviations from the Midas-Garch models and the cross-sectional annualized average of the 65-day rolling window return standard deviations. 